\title{
High glucose suppresses embryonic stem cell differentiation into cardiomyocytes
}

\section{High glucose inhibits ES cell cardiogenesis}

\author{
Penghua Yang ${ }^{1}$, Xi Chen ${ }^{1}$, Sunjay Kaushal ${ }^{2}$, E. Albert Reece ${ }^{1,3}$ and Peixin Yang ${ }^{1,3^{*}}$
}

\begin{abstract}
Background: Babies born to mothers with pregestational diabetes have a high risk for congenital heart defects (CHD). Embryonic stem cells (ESCs) are excellent in vitro models for studying the effect of high glucose on cardiac lineage specification because ESCs can be differentiated into cardiomyocytes. ESC maintenance and differentiation are currently performed under high glucose conditions, whose adverse effects have never been clarified.

Method: We investigated the effect of high glucose on cardiomyocyte differentiation from a well-characterized ESC line, E14, derived from mouse blastocysts. E14 cells maintained under high glucose (25 mM) failed to generate any beating cardiomyocytes using the hanging-drop embryonic body method. We created a glucose-responsive E14 cell line (GR-E14) through a graduated low glucose adaptation. The expression of stem cell markers was similar in the parent E14 cells and the GR-E14 cells.

Results: Glucose transporter 2 gene was increased in GR-E14 cells. When GR-E14 cells were differentiated into cardiomyocytes under low $(5 \mathrm{mM})$ or high $(25 \mathrm{mM})$ glucose conditions, high glucose significantly delayed the appearance and reduced the number of TNNT2 (Troponin T Type 2)-positive contracting cardiomyocytes. High glucose suppressed the expression of precardiac mesoderm markers, cardiac transcription factors, mature cardiomyocyte markers, and potassium channel proteins. High glucose impaired the functionality of ESC-derived cardiomyocytes by suppressing the frequencies of $\mathrm{Ca}^{2+}$ wave and contraction.
\end{abstract}

Conclusions: Our findings suggest that high glucose inhibits ESC cardiogenesis by suppressing key developmental genes essential for the cardiac program.

Keywords: Embryonic stem cells, Cardiogenesis, High glucose, Contracting cardiomyocytes

\section{Background}

Nearly $2 \%$ of all pregnancies are affected by pregestational diabetes [1]. Infants from pregestational diabetic mothers have a greater risk of structural birth defects including congenital heart defects (CHDs) than those from nondiabetic mothers [2]. CHDs are the most common congenital anomalies occurring in approximately 4 to 10 per 1000 live births [3]. Our previous studies have shown that pregestational diabetes induces oxidative

\footnotetext{
* Correspondence: pyang@fpi.umaryland.edu

'Department of Obstetrics, Gynecology and Reproductive Sciences, University of Maryland School of Medicine, BRB11-039, 655W. Baltimore Street, Baltimore, MD 21201, USA

${ }^{3}$ Department of Biochemistry and Molecular Biology, University of Maryland School of Medicine, Baltimore, MD 21201, USA

Full list of author information is available at the end of the article
}

stress and activates pro-apoptotic kinase signaling leading to endoplasmic reticulum stress, impaired cell proliferation, and apoptosis, which cause defective heart formation [4-12]. Additionally, maternal diabetes represses the expression of transcription factors that are essential for cardiac lineage specification $[5,8,9,13]$, suggesting that maternal diabetes adversely impacts cardiogenesis during early embryonic development. The objective of the present study is to study the effect of high glucose on ESC differentiation into cardiomyocytes.

Pluripotent embryonic stem (ES) cells, derived from the preimplantation embryo, can differentiate into derivatives of all three primary germ layers [14]. Since the first mouse and human ES cells were successfully isolated from blastocysts $[15,16]$, they have been widely 
used for the generation of differentiated cells including cardiomyocytes [17-20]. The ES differentiation process to cardiomyocytes is a unique in vitro model for studying the effect of high glucose on early cardiac lineage specification and cardiomyocyte maturation. Several procedures have been reported for cardiomyocyte differentiation from ES cells with different efficiencies [21-24]. ES differentiation procedures using kinase inhibitors or inhibitors of the Wnt signaling achieve a high yield of positive cardiomyocytes [25]; however, these inhibitors may adversely impact the function of resultant cardiomyocytes. Using the embryoid body (EB) hanging-drop method, a low number of contracting cardiomyocytes can be generated in regular medium without small molecules and kinase inhibitor treatment. Therefore, we used this method in our experiment.

Essentially, all ES cell differentiation procedures have been performed under high glucose conditions $(25 \mathrm{mM})$, which is not comparable to physiological concentration of glucose $(5 \mathrm{mM})$ [26]. ES cell differentiation into cardiomyocytes under physiological glucose conditions recapitulates the cardiac cell lineage specification during early embryogenesis. In the present study, the mouse ES cell line (E14), initially cultured under high glucose, was gradually adapted into low glucose conditions and eventually maintained under $5 \mathrm{mM}$ glucose conditions. The stemness of these adapted E14 cells, which were glucose responsive (GR-E14 cells), was not different with that of the parent E14 cells. Using the EB hanging-drop method, GR-E14 cells effectively generated contracting cardiomyocytes $(70 \%)$ under physiological glucose conditions. High glucose significantly delayed cardiogenesis and suppressed gene expression pertinent to cardiac lineage specification. Our study provides evidence that glucose is a crucial effector in ES cardiogenesis.

\section{Methods}

\section{mESCs maintenance}

The E14 mESC line and the D3 cell line derived from blastocysts [27] were purchased from ATCC (Manassas, VA, USA) and maintained in feeder-free conditions according to the ATCC instructions. Briefly, E14 mESCs were plated on 6-well culture plates coated with $0.1 \%$ gelatin in DMEM medium (DMEM, 15\% ES quality FBS, $1 \%$ NEAA, $1 \%$ glutamine, $1 \% \beta$-mercaptolethanol, 1000 $\mathrm{U} / \mathrm{ml}$ LIF, $1 \%$ antibiotics). Medium was changed daily. Regular subculture was performed by a ratio of 1 to 6 . E14 mECS line maintained under $25 \mathrm{mM}$ glucose medium was initially transferred to a medium with 11.1 $\mathrm{mM}$ glucose for eight passages and subsequently 8.3 $\mathrm{mM}$ glucose for another eight passages. The resulting E14 cells were then switched into medium with the physiological glucose concentration $(5 \mathrm{mM})$ for four passages. The same protocol was applied to the D3
mESC line. All of the experiments in this study began with E14 mES cells (called GR-E14) from passage 20 under $5 \mathrm{mM}$ glucose conditions.

\section{E14 cell differentiation to cardiomyocytes}

Cardiomyocytes were differentiated from GR-E14 cells via the hanging-drop method [28] in differentiation medium containing 5 or $25 \mathrm{mM}$ glucose (25\% DMEM, 25\% F12 medium, 50\% neurobasal medium, 1\% N2, $2 \%$ B27, $1 \%$ NEAA, $1 \%$ glutamine, $1 \% \beta$-mercaptolethanol, $1 \%$ antibiotics). GR-E14 cells at $80 \%$ confluence were dissociated with Accutase solution (Life Technologies, Grand Island, NY, USA) at $37{ }^{\circ} \mathrm{C}$ for 7 minutes, and the collected cells were adjusted to a concentration of $3.3 \times$ $10^{4}$ cells $/ \mathrm{ml}$. Fifty drops of $30 \mu \mathrm{l}$ cell suspension $(1000$ cells/drop) were seeded into the lid of a $10-\mathrm{cm}$ petri dish with $15 \mathrm{ml}$ PBS for EB formation for 3 days followed by suspension culture in a petri dish for an additional 2 days in medium containing $5 \mathrm{mM}$ or $25 \mathrm{mM}$ glucose. After 5 days, the formed EBs were transferred into 0.1\% gelatin-coated 6-well culture plates and cultured for an additional 7 to 9 days for cardiogenesis. Contracting EBs and cell colonies were monitored daily under microscopy. For counting the contracting EB number, 50 EBs per group were plated on a $10-\mathrm{cm}$ culture dish coated with $0.1 \%$ gelatin and were monitored daily under microscopy.

\section{Fluorescence-activated cell sorting (FACS)}

Cells at differentiation day 6,8 , and 10 were dissociated into single cells by Trypsin-EDTA and transferred to flow cytometry tubes (BD Biosciences, San Jose, CA, USA) followed by fixation and permeabilization using the BD Cytofix/Cytoperm Kit (BD Biosciences, San Jose, CA, USA) with addition of 1:200 mouse anti-Tnnt2 antibody (Sigma-Aldrich, St. Louis, MO, USA) for 30 minutes at room temperature. Secondary antibody staining was performed in 1:1000 Alexa Fluor 488 goat anti-mouse IgG1 for 30 minutes. Cells were analyzed using the FACSCanto II and the FACSDiva software (BD Biosciences, San Jose, CA, USA). Data were analyzed using the FlowJo 10.1 software (FlowJo, LLC, Ashland, OR, USA).

\section{RNA isolation and real-time PCR}

RNA was isolated with Trizol reagent (Invitrogen, Grand Island, NY, USA) from cells at different differentiation days according to the manufacturer's instruction. cDNAs were synthesized from $1 \mu \mathrm{g}$ total RNA by the Quantitect Reverse Transcription Kit (Qiagen, Valencia, CA, USA). The real-time qPCR for Oct4, Sox2, Lin28, Klf2, T, Glut2, Mixl1, Gata4, Tbx5, Nkx2.5, Mef2c, TnnT2, SERCA2A, RYR2, Hcn1-4, and Kcn1 were performed by the $\mathrm{Rt}^{2}$ Sybr Green Rox qPCR Mastermix (Qiagen, Valencia, CA, USA) in the StepOnePlus system (Applied 
Biosystems, Grand Island, NY, USA). Primer sequences for qPCR are listed in the Additional file 1: Table S1.

\section{Western blotting}

A total of 30-50 $\mu \mathrm{g}$ protein from cells at differentiation day 9 was extracted using the cell lysis buffer (Cat\# 9803, Cell Signaling, Danvers, MA, USA) containing a $1 \%$ protease inhibitor cocktail (Sigma-Aldrich, St. Louis, MO, USA), $1 \%$ PMSF, $2 \%$ sodium fluoride, and $2 \%$ sodium orthovanadate. Immunobilon-P (EMD Millipore, Billerica, MA, USA) membranes were used for immunoblotting. Membranes were sequentially exposed to mouse anti-GATA4 (1:1000, Origene, Rockville, MD, USA), rabbit anti-TBX5 (1:1000, Life Technologies, Grand Island, NY, USA), mouse anti-MEF2C (1:1000, Thermo Fisher Scientific, Waltham, MA, USA), rabbit anti-KCN1 (1:1000, Prosci Inc., San Diego, CA, USA) and rabbit anti-TnnT2 (1:1000, Origene, Rockville, MD, USA) overnight followed by incubation of goat antirabbit IgG or goat anti-mouse IgG conjugated with HRP (1:10,000, Jackson ImmunoResearch Laboratories, West Grove, PA, USA) for 4 hours. Signals were detected using the SuperSignal West Femto Maximum Sensitivity Substrate Kit (Pierce Biotechnology, Rockford, IL, USA) and chemiluminescence emitted from the bands was directly captured using the UVP Bioimage EC3 system. Densitometric analyses of chemiluminescence signals were performed using the VisionWorks LS software (UVP, Upland, CA, USA).

\section{Immunofluorescence}

EBs were plated onto $0.1 \%$ gelatin-coated chamber slides (Thermo Fisher Scientific, Waltham, MA, USA) in high or low glucose medium. At differentiated day 7 to 9 , cells were fixed by $4 \%$ paraformaldehyde for 10 minutes at room temperature followed by permeabilization with $0.05 \%$ TritonX-100 for 10 minutes. Samples were blocked for 1 hour with 10\% heat-inactivated donkey serum in PBS and incubated with the following antibodies: TNNT2 (1:200, Origene, Rockville, MD, USA), NKX2.5 (1:200, Sigma-Aldrich, St. Louis, MO, USA), and HCN1 (1:200, Sigma-Aldrich, St. Louis, MO, USA), overnight at $4{ }^{\circ} \mathrm{C}$. After washing with PBS three times, cells were incubated with a Cy3-conjugated secondary antibody (diluted 1:1000) at room temperature for 4 hours followed by incubation with DAPI for 10 minutes and mounted with aqueous mounting medium. Fluorescence image were taken on Nikon H600L microscope (Nikon, Tokyo, Japan) with the IPLab imaging system (Scientific Instrument Company, San Diego, CA, USA).

\section{$\mathrm{Ca}^{2+}$ imaging}

Differentiated EB in low or high glucose conditions were placed on gelatin-coated chamber slides (Lab-Tek,
Thermo Fisher Scientific, Waltham, MA, USA) for $\mathrm{Ca}^{2+}$ imaging based on a previously described protocol [29]. ES-derived cardiomyocytes at day 9 were loaded with 5 $\mu \mathrm{M}$ fluo 4-AM (Thermo Fisher Scientific, Waltham, MA, USA) for 20 minutes at room temperature and replaced with normal Tyrode's solution containing (in $\mathrm{mM}) 140 \mathrm{NaCl}, 10$ Hepes, $0.5 \mathrm{MgCl}_{2}, 0.33 \mathrm{NaHPO}_{4}$, 5.5 glucose, $1.8 \mathrm{CaCl}_{2}$, and $5 \mathrm{KCl}(\mathrm{pH} \mathrm{7.4)}$. Confocal imaging (Zeiss LSM-510; Carl Zeiss, Oberkochen, Germany) was used to monitor $\mathrm{Ca}^{2+}$ signals using a line scan method for 10,000 time at $1.93 \mathrm{msec}$ per line. Data were analyzed using ImageJ (NIH, Bethesda, MD, USA).

\section{Statistical analysis}

Data was analyzed by the Sigmaplot 12.5 software (Systat Software Inc, San Jose, CA, USA). Experiments were repeated independently three times. Data are presented as mean \pm SD. Statistical differences were evaluated using one-way analysis of variance (ANOVA) followed by the Tukey test.

\section{Results}

E14 cells adapted to physiological glucose concentrations retain stemness and have a high expression of glucose transporter 2

Like most ES cell lines, the E14 cell is maintained under high glucose conditions ( $25 \mathrm{mM}$ glucose). In order to assess the effect of high glucose on ES cell differentiation, it is essential to establish an ES cell line which is adapted to the physiological glucose concentration $(5 \mathrm{mM})$. Here, we showed a simple and cost-saving method for the establishment of an E14 cell line adapted to physiological glucose conditions by gradually lowering the glucose concentration to $5 \mathrm{mM}$ in culture medium as described in the "Methods" section. The expression of pluripotent markers, OCT4, SOX2, LIN28, and KLF2, in the glucose-adapted E14 cell line was similar to that in the parent E14 cell line that was maintained under high glucose conditions (Fig. 1a). It has been shown that an ES cell line established under low glucose conditions expresses higher levels of glucose transporter 2 (Glut2) comparing with those in an ES cell line cultured in high glucose [30]. Glut2 expression was significantly higher in the low glucose-adapted E14 cells than in the parent E14 cells (Fig. 1b), suggesting that the low glucose-adapted E14 cells are glucose responsive (GR-E14 cells). Embryoid bodies derived from GR-E14 cells had a similar expression of SOX1, Brachyury (T), and AFP as that in the parent E14 cells (Fig. 1c), indicating that the GR-E14 cells retained the capability of differentiation into all three primary germ layers. 

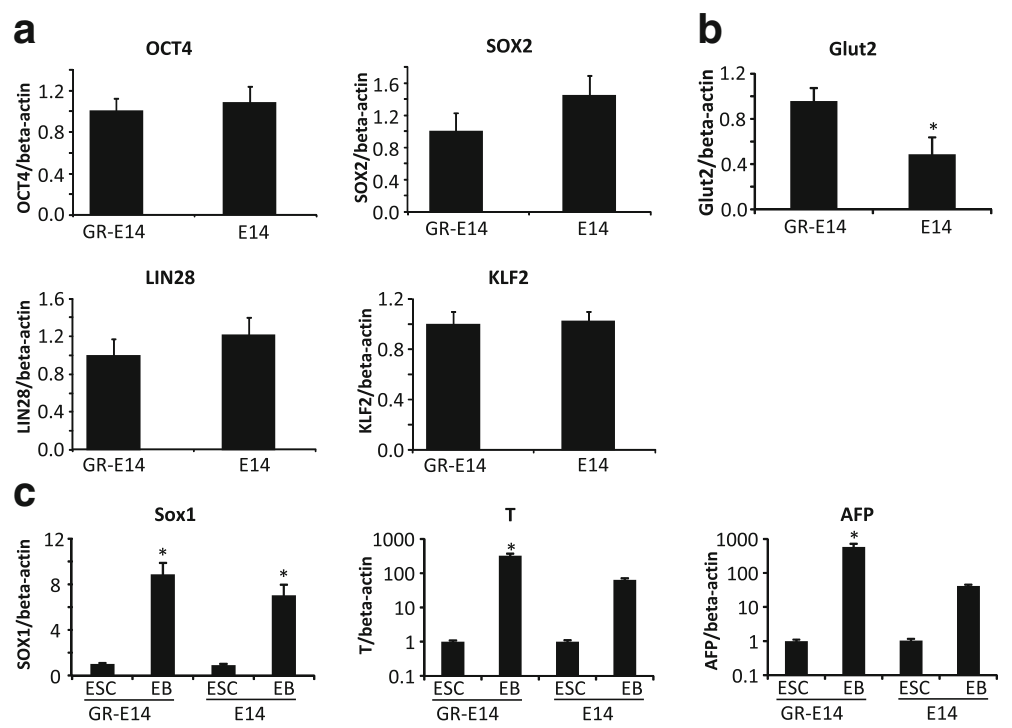

Fig. 1 Characteristics of parent E14 cells and the GR-E14 cells adapted to low glucose. a mRNA levels of pluripotent markers, OCT4, SOX2, KLF2, and LIN28, in parent E14 cells and E14 cells adapted to low glucose (GR-E14 cells). b Glut2 mRNA levels in GR-E14 and parent E14 cells. c mRNA levels of ectoderm marker SOX1, mesoderm marker T, and endoderm marker AFP in EBs. E14 E14 cells maintained under 25 mM glucose condition, EB embryoid body derived from E14 or GR-E14 cells, GR-E14 glucose-responsive E14 cell line, which was gradually adapted to 5 mM glucose medium from $25 \mathrm{mM}$ glucose medium. All experiments were repeated three times $(n=3)$, the value was dedicated as mean \pm SD. ${ }^{*}$ Indicates significant difference compared with the other group(s)

\section{High glucose suppresses the differentiation of GR-E14 cells into contracting cardiomyocytes}

CHDs frequently occur in babies whose mothers have diabetes [31]. Previous studies have demonstrated that the high glucose of diabetes suppresses gene expression related to apoptosis, proliferation, and migration in the developing heart [13, 31, 32]. However, early development events such as the ontogeny of cardiomyocytes from ES cells may be affected by high glucose and thus contribute to the etiology of CHD formation in diabetic pregnancies. We hypothesize that high glucose suppresses ES cardiogenesis. To test this hypothesis, embryoid bodies (EBs) were formed for 5 days with the hanging-drop method prior to further differentiation into cardiomyocytes [33, 34], (Fig. 2a). When the parent E14 cells, which are accustomed to high glucose, were used for differentiation into cardiomyocytes under either low glucose $(5 \mathrm{mM})$ or high glucose $(25 \mathrm{mM})$ conditions, very few EBs derived from these cells could attach to surfaces of culture plates coated with $0.1 \%$ gelatin at the first day of differentiation (Fig. 2b). Even after 5 days, only few EBs attached to culture plates (Fig. 2c), and none of these attached EBs could differentiate to contracting cardiomyocytes (data not included). In contrast, most of the EBs derived from GR-E14 cells (93.3 $\pm 4.6 \%$ in $5 \mathrm{mM}$ glucose and $74.0 \pm 4.0 \%$ in $25 \mathrm{mM}$ glucose) attached to culture plates at the first day of differentiation and remained attached at high numbers in day 5 (Fig. 2b and c). Therefore, we only focused on GR-E14 for further experiments to assess the effect of high glucose.

For the differentiation of GR-E14 cells, contracting EBs or cardiomyocytes appeared at day 6 in $5 \mathrm{mM}$ glucose and at day 8 in high glucose $(25 \mathrm{mM})$ medium, respectively (Fig. 2d). Thus, high glucose delayed GR-E14 cell cardiogenesis for 2 days (Fig. 2d). Whereas $70.0 \pm$ $4.0 \%$ of the EBs were differentiated into contracting cardiomyocytes in $5 \mathrm{mM}$ glucose at day 10 , only $14.7 \pm 1.2 \%$ contracting EBs were obtained under high glucose (25 $\mathrm{mM}$ ) conditions (Fig. 2d).

The contracting colony number in $5 \mathrm{mM}$ glucose at day 8 of differentiation was significantly higher than that in high glucose (Fig. 2e). At day 10 of differentiation, the contracting colony number in $5 \mathrm{mM}$ glucose $(109.7 \pm$ 10.2) was significantly higher than that under high glucose condition $(29.0 \pm 4.0),(P<0.01)$ (Fig. 2e). Moreover, the percentage of contracting colonies in $5 \mathrm{mM}$ glucose achieved $5.53 \pm 1.35 \%$ at day 6 . However, it took 10 days to achieve a similar contracting colonies ratio (4.83 \pm $0.67 \%$ ) in $25 \mathrm{mM}$ glucose (Fig. 2f). Furthermore, the contracting frequency of contracting colonies in $5 \mathrm{mM}$ glucose was significantly higher than that in $25 \mathrm{mM}$ glucose at day 10 of differentiation (Fig. $2 \mathrm{~g}$ and Additional file 2: Video 1 and Additional file 3: Video 2).

To further determine if cardiogenesis was affected by high glucose, FACS was performed to detect TNNT2 frequencies in differentiated cells. Consistent with our 


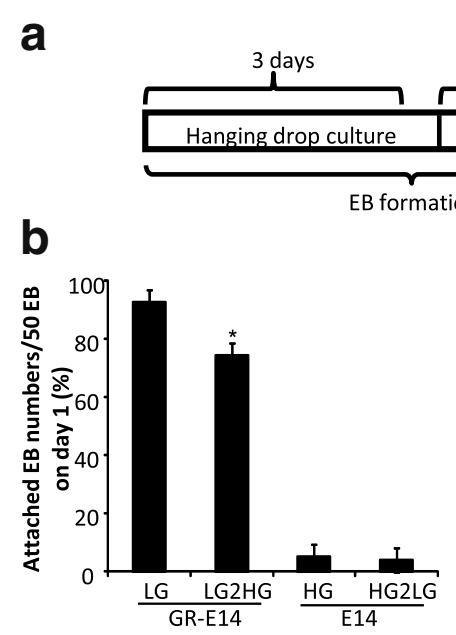

Initiation of attached differentiation

(Day 0)
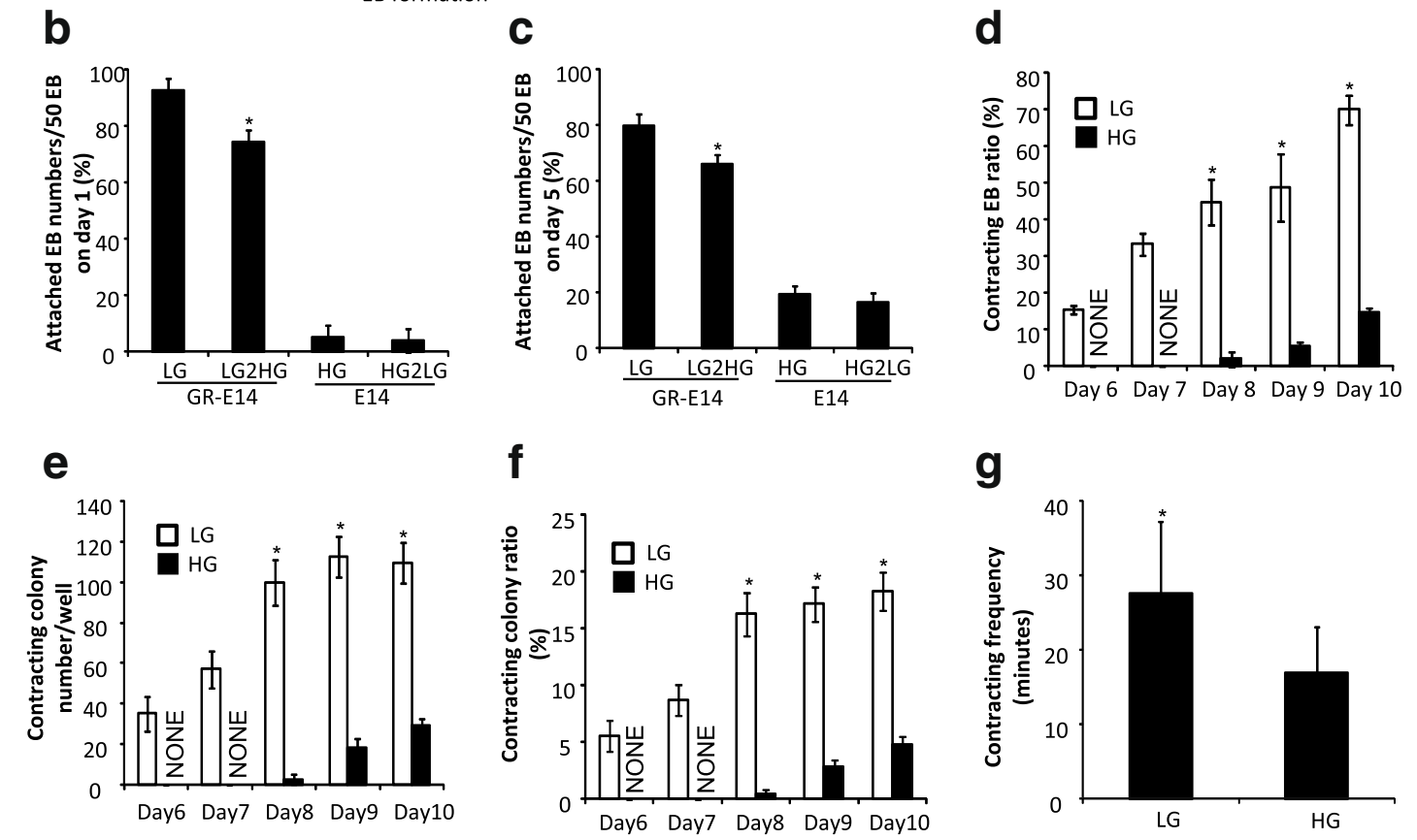

h

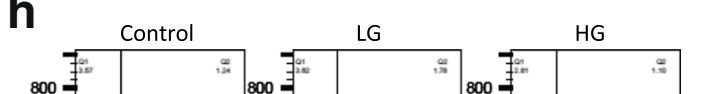

j
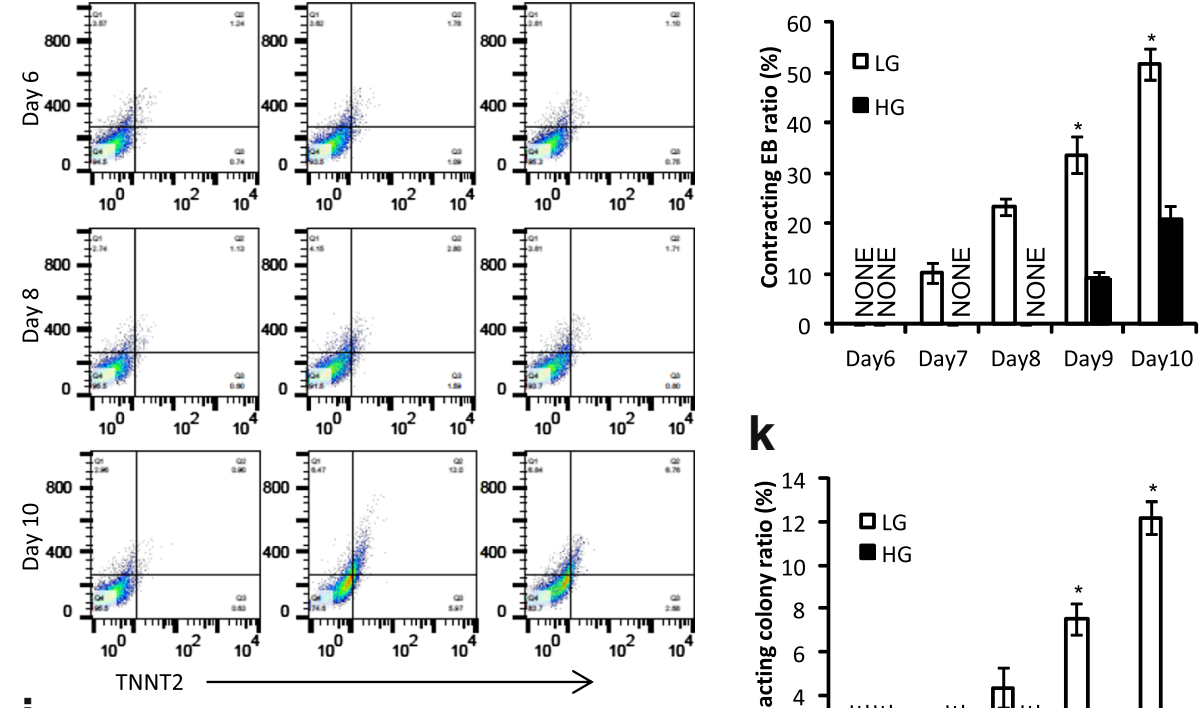

$\mathbf{k}$

i
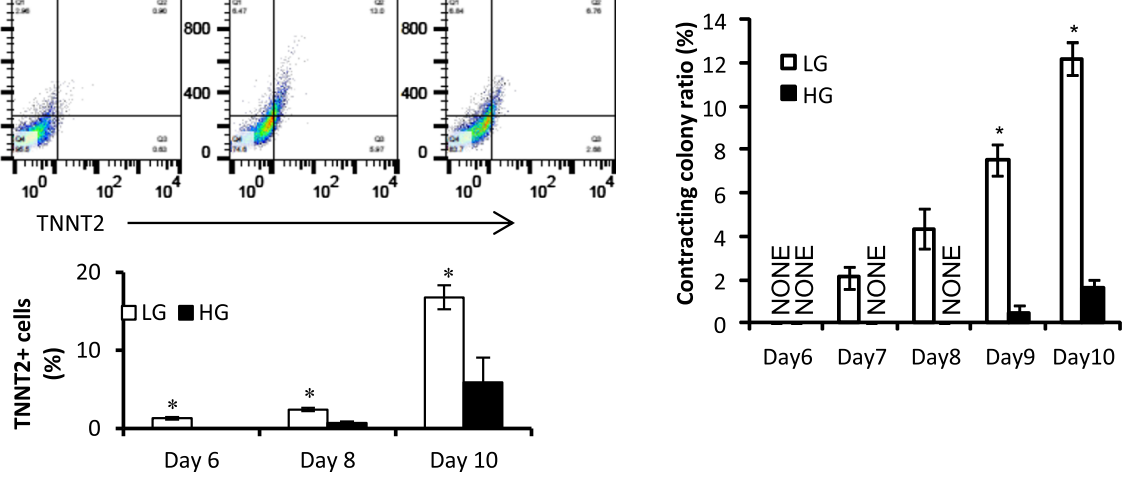

Fig. 2 (See legend on next page.) 
(See figure on previous page.)

Fig. 2 High glucose suppresses GR-E14 cell cardiogenesis. a Schematic diagram of ES cell cardiomyocytes. Hanging-drop culture was performed with one drop of $30 \mu \mathrm{l}$ medium per 1000 cells for 3 days for EB formation, and then suspension culture was done in a 10-cm petri dish for another 2 days for EB growth followed by differentiation. $\mathbf{b}$ The numbers of EB attached to the culture plate on day 1 after seeding the formed EBs (differentiation). $\mathbf{c}$ The numbers of EB attached to the culture plate on day 5 of differentiation. GR-E14 cells adapted to low glucose were used for hanging-drop culture in low glucose $(5 \mathrm{mM}, L G)$ or high glucose $(25 \mathrm{mM})$ medium $(L G 2 H G)$, parent E14 cells maintained in high glucose medium were used for hanging-drop culture in HG or low glucose medium (HG2LG). d The percentage of contracting EBs in GR-E14 cells under LG/HG condition. Fifty EBs per group $(n=3)$ were used for cardiogenesis and the contracting EB percentage was calculated by the formula: (number of contracting EBs/number of total EBs) $\times 100 \%$. e Numbers of contracting colonies from GR-E14 cells under LG/HG conditions. At day 5 of EB formation, an aliquot of $10 \mu \mathrm{l} \mathrm{EB}$ suspension, containing $20 \mathrm{EBs}$ (equivalent to $5 \times 10^{5} \mathrm{cells}$ ), was seeded into a well of a 6-well culture plate for cardiogenesis. $\mathbf{f}$ Percentage of contracting colonies from GR-E14 cells under LG/HG conditions. The contracting colony percentage was calculated by the formula: (number of contracting colonies/number of total colonies) $\times 100 \%$. $\mathbf{g}$ Frequencies of contracting colonies from GR-E14 under LG/HG conditions. $\mathbf{h}$ The frequencies of TNNT2+ cardiomyocytes at day 6 (left), day 8 (middle) and day 10 (right) after differentiation. HG high glucose $\left(25 \mathrm{mM}\right.$, red), LG low glucose $\left(5 \mathrm{mM}\right.$, gray). i Percentages of TNNT2 ${ }^{+}$cardiomyocytes differentiated from GR-E14 cells. TNNT2 ${ }^{+}$cell percentages $(\%)=\left(\mathrm{TNNT2}^{+}\right.$cell number/total cell number $) \times 100 \%$. Total cell number is 10,000 per group. $\mathbf{j}$ The percentage of contracting EBs in D3 cells under LG/ HG conditions. The protocol was the same as that of GR-E14. $\mathbf{k}$ Percentage of contracting colonies from D3 cells under LG/HG conditions. The protocol was the same as that of GR-E14. E14 E14 cells maintained under $25 \mathrm{mM}$ glucose condition, GR-E14 glucose-responsive E14 cell line, which was gradually adapted to $5 \mathrm{mM}$ glucose medium from $25 \mathrm{mM}$ glucose medium. All experiments were repeated three times $(n=3)$. Data were expressed as mean \pm SD. Indicate significant difference compared with the other group(s)

finding above, TNNT2-positive cells emerged at day 6 in 5 $\mathrm{mM}$ glucose, but were not present in $25 \mathrm{mM}$ glucose (Fig. $2 \mathrm{~h}$ and i). Additionally, the TNNT2-positive cell number in $25 \mathrm{mM}$ glucose was significantly lower than that in $5 \mathrm{mM}$ glucose medium at day $8.16 .8 \pm 1.5 \%$ of TNNT2-positive cardiomyocytes were observed in $5 \mathrm{mM}$ glucose at day 10 , whereas only $6.0 \pm 3.1 \%$ of TNNT2positive cardiomyocytes were obtained in $25 \mathrm{mM}$ glucose medium. Collectively, these data demonstrate that high glucose suppresses GR-E14 cell cardiogenesis.

To further confirm our finding, another mouse ES cell line, D3, was adapted into low glucose and differentiated into cardiomyocytes using the same method described above. For the differentiation of D3 cells, contracting EBs or cardiomyocytes appeared at day 7 in $5 \mathrm{mM}$ glucose and at day 9 in high glucose $(25 \mathrm{mM})$ medium, respectively (Fig. 2j, k). Thus, consistent with the observation in GR-E14 cells (2d, e), high glucose delayed D3 cell cardiogenesis for 2 days (Fig. 2 d). $51.7 \pm 3.1 \%$ of the EBs were differentiated into contracting cardiomyocytes in $5 \mathrm{mM}$ glucose at day 10 , whereas only $21.0 \pm$ $1.6 \%$ contracting EBs were obtained under high glucose (25 mM) conditions (Fig. 2j). Furthermore, the contracting colonies ratio in $25 \mathrm{mM}$ glucose was also significantly lower than that in $5 \mathrm{mM}$ glucose (Fig. 2k). However, the differentiation efficiency of the D3 cell line was lower than that of GR-E14 (Fig. 2d, j), the following experiments were performed on GR-E14 cells only.

\section{High glucose represses gene expression essential for cardiogenesis}

To determine whether high glucose affects the expression of early cardiac markers, we detected precardiac mesoderm marker, Brachyury ( $\mathrm{T}$ ) and Mixl1, and heart field-specific progenitor markers, NKX2.5, TBX5, and GATA4. The expression of T and Mixl1 in $5 \mathrm{mM}$ glucose was significantly higher than that in high glucose $(25 \mathrm{mM})$ before day 5 of differentiation (Fig. 3a). More interestingly, the expression of heart field-specific progenitor markers, NKX2.5, TBX5, and GATA4, in $5 \mathrm{mM}$ glucose was significantly higher than that in high glucose (Fig. 3b). Specifically, GATA4 expression in $5 \mathrm{mM}$ glucose was significantly higher than that in high glucose at the EB stage and throughout the entire course of differentiation (Fig. 3b). Furthermore, $45.4 \pm 3.7 \%$ of NKX2.5-positive cells were observed in $5 \mathrm{mM}$ glucose; however, $26.4 \pm 2.3 \%$ cells were NKX2.5-positive in high glucose (Fig. 3c, d). TBX5 and GATA4 protein levels were also suppressed by high glucose (Fig. 3e). Thus, high glucose suppresses cardiac gene expression during GR-E14 cardiogenesis.

\section{High glucose inhibits the maturation of differentiated cardiomyocytes}

Because high glucose significantly decreased the number of contracting cardiomyocytes, we next assessed the expression of mature cardiomyocyte markers, TNNT2 and MEF2C, during differentiation of GR-E14 cells into cardiomyocytes. At day 7 of differentiation, MEF2C and TNNT2 levels were significantly higher in $5 \mathrm{mM}$ glucose than those in high glucose (Fig. 4a). Coinciding with mRNA expression, TNNT2 immunofluorescent staining showed a significantly higher number of TNNT2-positive cells in $5 \mathrm{mM}$ glucose compared with high glucose (Fig. 4b, c). Total cellular MEF2C and TNNT2 protein levels were significantly reduced by high glucose (Fig. 4d).

These findings demonstrate that cardiomyocyte maturation is attenuated by high glucose.

High glucose reduces the expression of potassium channel proteins that are essential for cardiomyocyte contraction Cardiomyocyte contracting function is highly associated with calcium-handling process and several ion channels 

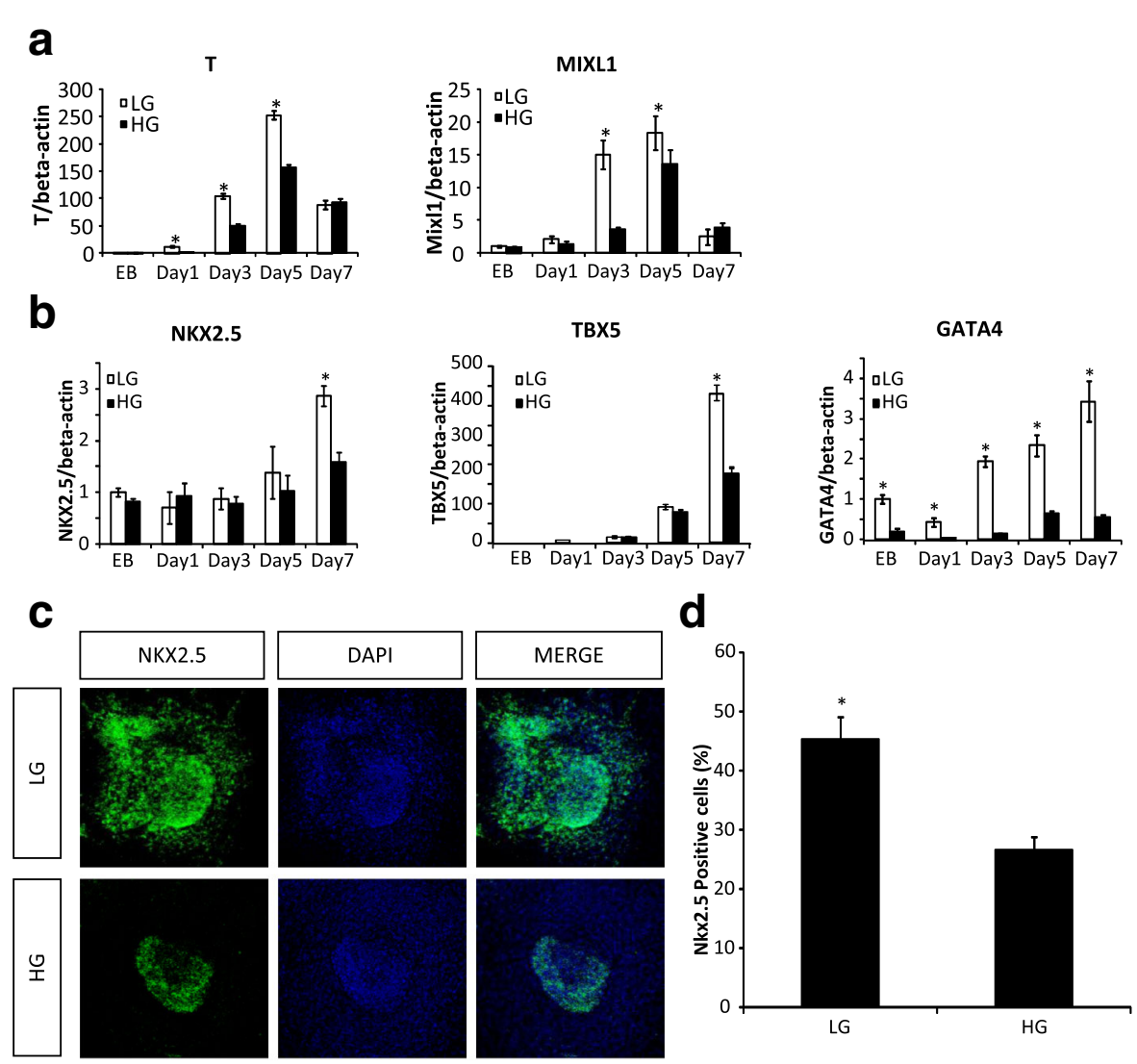

d
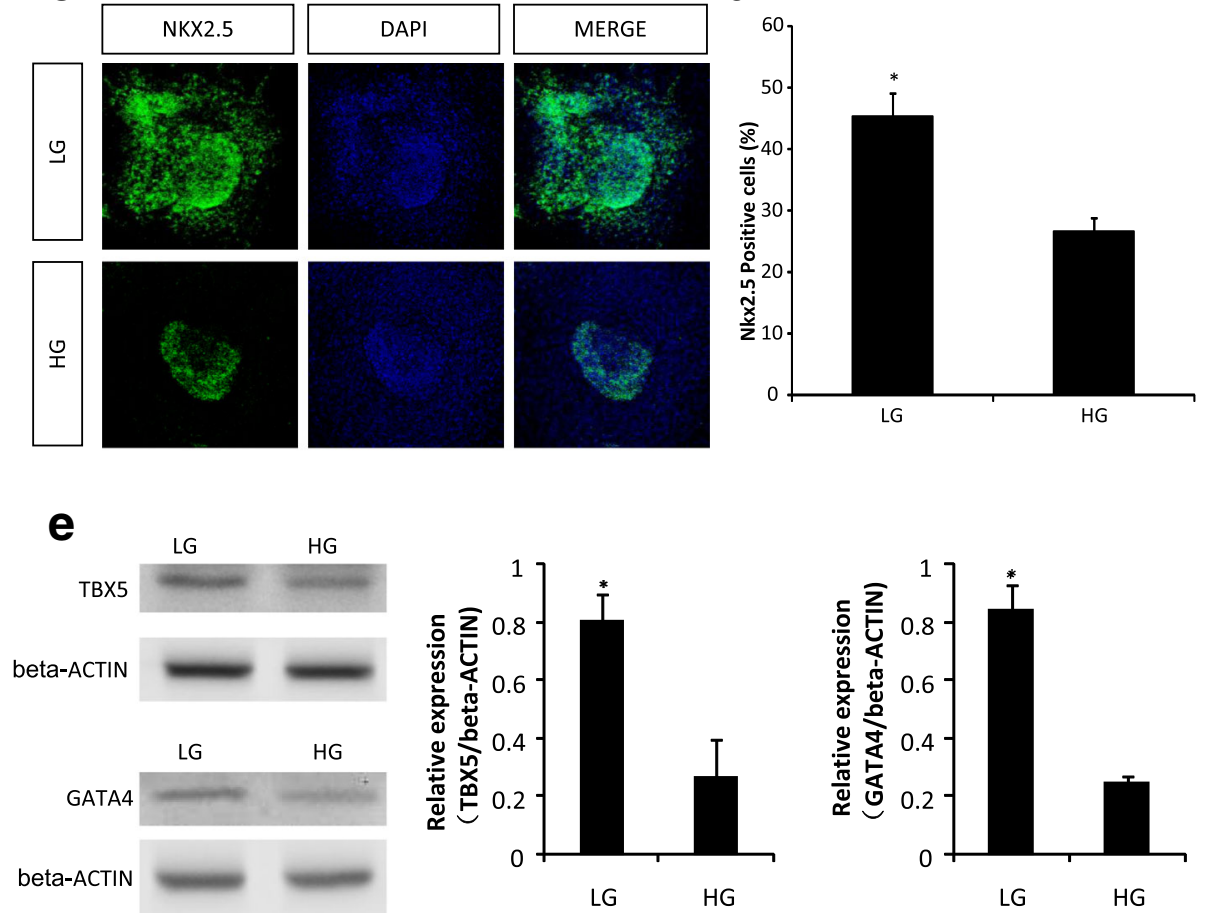

Fig. 3 High glucose inhibits gene expression essential for cardiogenesis. a mRNA levels of mesodermal markers, T, and MIXL1 during GR-E14 cell cardiogensis. b mRNA levels of cardiac transcription factors, NKX2.5, TBX5, and GATA4. c Representative images of NKX2.5 immunofluorescent staining (green). DAPI (blue) was for cell nuclei staining. d Quantitative fluorescent density data of NKX2.5 immunofluorescent staining. e TBX5 and GATA4 protein levels at differentiation day 7. Gene expression was assessed at EB formation day 5 and attachment culture (differentiation) at day $1,3,5$, and 7. Experiments were repeated three times $(n=3)$. EB embryoid body derived from E14 or GR-E14 cells, HG high glucose $(25 \mathrm{mM}), L G$ low glucose $(5 \mathrm{mM})$. Values were dedicated as mean \pm SD. ${ }^{*}$ Indicates significant difference compared with the other group

$[35,36]$. Among them, the hyperpolarization-activated cyclic nucleotide-modulated (HCN) channels contribute to a faster rhythmicity of beating mouse cardiomyocytes derived from ES cells [37, 38]. To understand the impaired contraction of cardiomyocytes by high glucose, we detected the expression of several ion channels genes, including Cav1.2, Nav1.5, HCN1-4, KCN1, and calcium-handling genes, SERCA2A and RYR2. High glucose did not affect the expression of the two main calcium-handling genes, SERCA2A and RYR2 (Fig. 5a). However, the expression of the potassium channels, HCN1 and KCN1, was significantly decreased by high glucose beginning at day 5 of differentiation before ontogeny of beating cardiomyocyte at day 6 (Fig. 5b). Moreover, there are more HCN1-positive cells in $5 \mathrm{mM}$ than in high glucose (Fig. 5c and d). Total cellular KCN1 protein levels were significantly reduced by high glucose (Fig. 5e). Furthermore, the functionality of ES-derived 


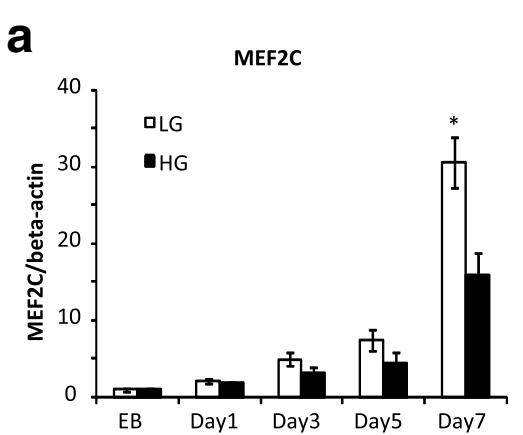

b
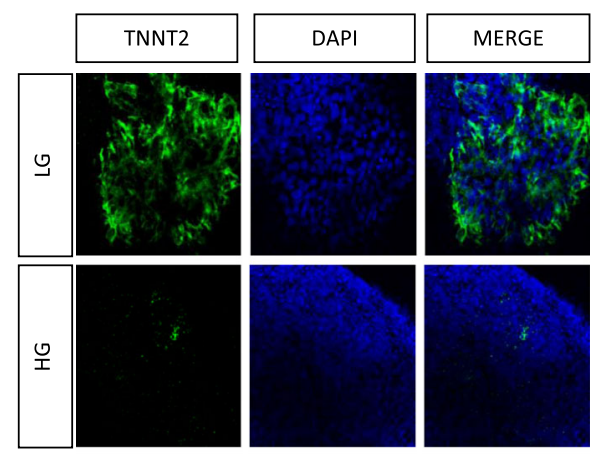

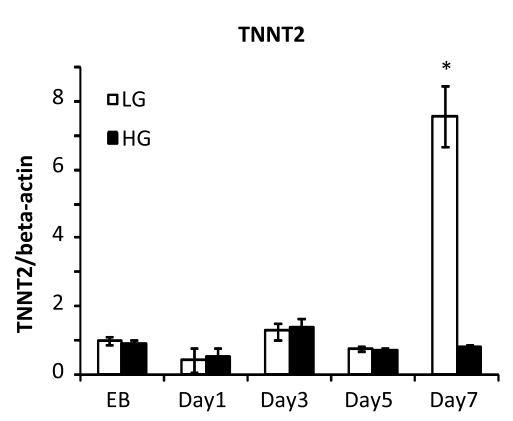

C

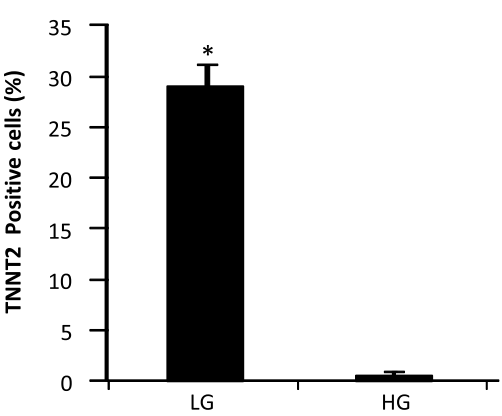

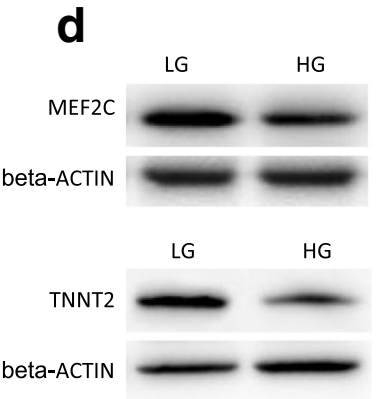
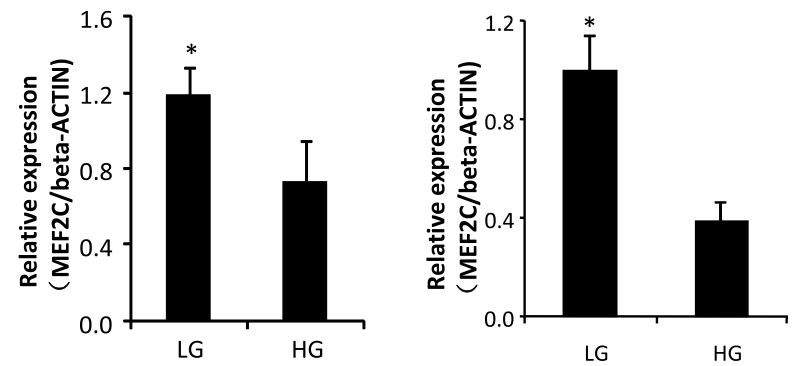

Fig. 4 High glucose suppresses cardiomyocyte-specific marker expression. a mRNA levels of cardiomyocyte structure proteins, MEF2C, and TNNT2. b Representative images of TNNT2 immunofluorescent staining. c Quantitative fluorescent density data of TNNT2 immunofluorescent staining. d MEF2C and TNNT2 protein expression at differentiation day 9. Gene expression was assessed at EB formation day 5 and differentiation day 1, 3, 5, and 7. Experiments were repeated three times $(n=3)$. EB embryoid body derived from E14 or GR-E14 cells, HG high glucose $(25 \mathrm{mM}), L G$ low glucose $(5 \mathrm{mM})$. Values were dedicated as mean \pm SD. ${ }^{*}$ Indicates significant difference compared with the other group

cardiomyocytes under high glucose condition was determined by $\mathrm{Ca}^{2+}$ wave profile. High glucose significantly suppressed the frequency of $\mathrm{Ca}^{2+}$ wave in differentiated cardiomyocytes (Fig. $5 \mathrm{f}$ and g). Consistent with the reduced $\mathrm{Ca}^{2+}$ wave frequency, high glucose inhibited the contracting frequency of contracting colonies (Fig. $2 \mathrm{~g}$ and Additional file 2: Video 1, and Additional file 3: Video 2). These results indicate that the decreased potassium channel expression may contribute to the impaired contraction of cardiomyocytes in high glucose.

\section{Discussion}

The precise temporal regulation of thousands of genes that govern developmental decisions is required during heart development [39]. However, gene expression patterns during developmental transitions to cardiac lineage are still not well understood. Cardiomyocyte differentiation derived from ES cells is a widely used model for studies in mimicking early cardiomyocyte development in vivo. There is a number of robust protocols for ES cell cardiogenesis including the EB hanging-drop method, which have provided many pivotal clues for understanding heart lineage specification [25]. Surprisingly, most ES cell maintenance and differentiation conditions are at high glucose conditions, often with $25 \mathrm{mM}$ glucose [40]. High glucose may adversely impact ES cardiogenesis. The effect of glucose on ES cell cardiogenesis has been previously assessed [40]. It has been shown that $25 \mathrm{mM}$ 
a

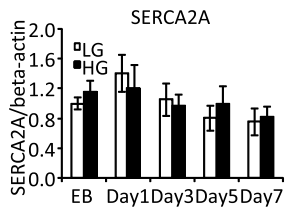

C

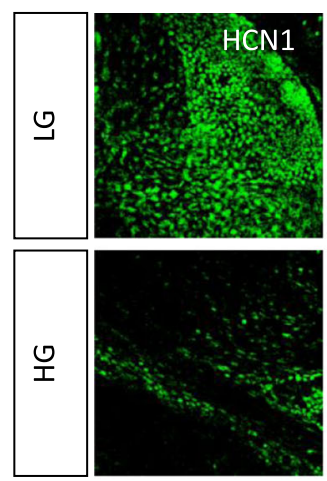

e
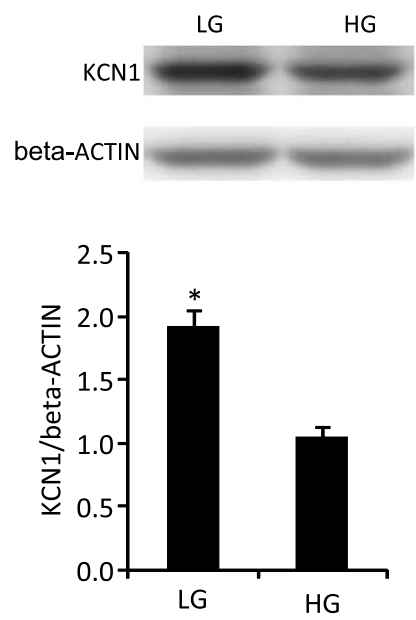

b
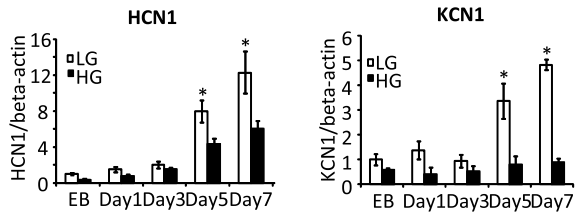

d
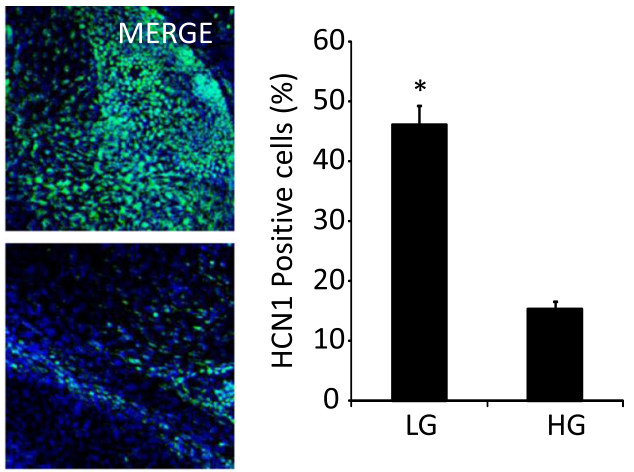

HG

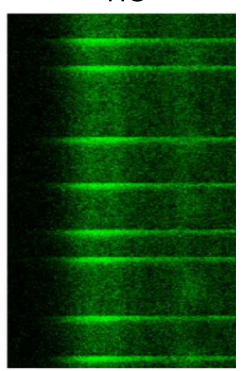

g
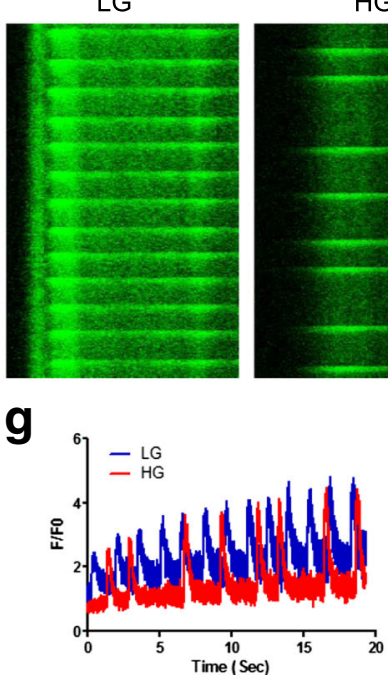

Fig. 5 The inhibitory effect of high glucose on calcium-handling and potassium channel gene expression during GR-E14 cardiogenesis. a mRNA levels of calcium-handling genes, SERCA2A and RYR2. $\mathbf{b}$ mRNA levels of potassium channel genes, HCN1 and KCN1. c Representative images of HCN1 immunofluorescent staining (green). DAPI (blue) was for cell nuclei staining. d Quantitative fluorescent density data of HCN1 immunofluorescent staining. e KCN1 protein expression at differentiation day 9. Gene expression was assessed at EB formation day 5 and differentiation day 1, 3, 5, and 7.

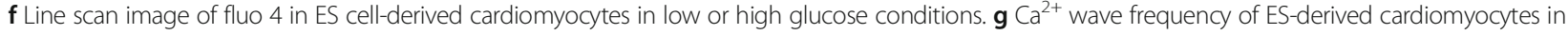
low or high glucose conditions. Experiments were repeated three times $(n=3)$. EB embryoid body derived from E14 or GR-E14 cells, HG high glucose (25 mM), LG low glucose (5 mM). Values were dedicated as mean \pm SD. Indicates significant difference compared with the other group

glucose supported ES cardiogenesis through reactive oxygen species (ROS), whereas $5 \mathrm{mM}$ glucose did not generate any contracting cardiomyocytes [40]. However, the ES cells in this previous study were generated and maintained under high glucose and just adapted to low glucose for a short time, two passages, prior to differentiation [40]. Due to this short low glucose adaptation, the ES cells may not acquire glucose responsiveness.
Indeed, they did not assess glucose responsiveness of ES cells before differentiation [40]. Therefore, whether these short-term low glucose-adapted cells responded to high glucose was unknown. In contrast, we obtained an ES cell line, GR-E14, which is adapted to low glucose condition through a 20 passage graduated glucose reduction, and acquires glucose responsiveness before differentiation. The GR-E14 cells can propagate in a long-term 
fashion without losing any stemness and pluripotency. A recent report demonstrated that ES cells established under low glucose condition possessed glucose responsiveness similar to cells of preimplantation and early postimplantation embryos by manifesting high Glut2 expression [30]. The GR-E14 cell line also expresses high levels of Glut2, implicating its glucose responsiveness. Indeed, subsequent studies demonstrated that high glucose adversely affected GR-E14 cardiogenesis.

The parent E14 cells accustomed to high glucose failed to generate any contracting cardiomyocytes using the hanging-drop method. It has been reported that ES cells generated and maintained under high glucose conditions can be differentiated into contracting cardiomyocytes [28]. ES cell cardiogenesis depends on the differentiation microenvironment [41], especially the starting ES cell number, the volume of hanging drops as well as the time of EB adherence to gelatin-coated plates [42]. The discrepancy between our study and those of others may be due to different settings of the hanging-drop method. In Crespo's study, ES cells were only passaged twice in low (5 mM) glucose medium [40]. However, in the present study, ES cells were passaged 20 times with gradually decreased glucose levels. GR-E14 cells were completely adapted in low glucose conditions and had a high pluripotent potential. Second, the EB formation protocols between ours and Crespo's were different. They performed 2 days of EB formation in hanging drop followed by adhesion differentiation on gelatin-coated dishes. However, 5 days of EB formation protocol including 3 days hanging drop and 2 days suspension culture were performed in our study. Third, the hanging-drop settings were also different. Settings of 1000 cells/30 $\mu \mathrm{l} /$ drop were used in the present study for 3 days, whereas 1000 cells/20 $\mu \mathrm{l} /$ drop were used in Crespo's study for 2 days. All of these differences may account for the discrepancy between the two studies. Nevertheless, GR-E14 cells can be differentiated into contracting cardiomyocyte at very high efficiency and GR-E14 cell cardiogenesis is subjected to glucose regulation, suggesting that our hanging-drop method settings are ideal for studies in glucose regulation of ES cell cardiogenesis. High glucose suppresses GR-E14 cell cardiogenesis by delaying the ontogeny of contracting EBs and reducing EB contraction frequencies. Previous studies have shown that heart rates are lower in the offspring of diabetic mothers than nondiabetic mothers [43]. Thus, the GR-E14 cell line is a useful in vitro model in mimicking the abnormal cardiogenesis of embryos exposed to pregestational diabetes.

CHDs are the most common defects in offspring of diabetic mothers [31]. Previous studies have shown that gene dysregulation is critically involved in diabetesinduced CHDs [13]. Our previous studies have determined that oxidative stress, endoplasmic reticulum stress and pro-apoptotic kinase signaling mediate the teratogenicity of diabetes in the developing heart by modulating gene expression $[4-6,8]$. To reveal the etiology of diabetes-induced CHDs, it is critical to understand the gene alterations during early cardiogenesis. A highly conserved gene regulatory network controls the initial differentiation, proliferation, and maturation of cardiomyocytes [21]. The anteriorly migrated mesoderm cells, once received appropriate signals, switch on a highly conserved cardiac transcriptional program via sequentially expressing heart-specific transcription factors [44]. Initially, Brachyury ( $\mathrm{T})$ and Mixl1-positive mesodermal precursor cells enter a precardiac mesoderm stage as evidence of Mesp1 expression [45, 46]. Subsequently, Mesp1-positive cells begin to express NKX2.5 and TBX5, which combined with GATA4 to activate cardiac structural genes such as TnnT2, MHC, and MLC [44]. Any abnormalities in this cardiac specification program result in CHDs. Mesodermal precursor cell markers, $\mathrm{T}$ and Mixl1, were suppressed by high glucose during early GR-E14 cardiogenesis. T deficiency in mice resulted in early embryonic lethality due to defects in mesoderm formation [47]. Mixl1 is required for axial mesendoderm morphogenesis in differentiating ES cells and murine embryos $[48,49]$. Suppression of both $T$ and Mixl1 may be a primary cause of abnormality in GR-E14 cardiogenesis by high glucose. Nkx2.5, the earliest known marker of the cardiac lineage in vertebrate embryos, is expressed in mouse embryo from E7.5 onward and its deletion causes CHDs resembling those in diabetic pregnancies $[50,51]$. NKX2.5, TBX5, and GATA4 expression were suppressed by high glucose. Consistent with the downregulation of these three cardiac transcription factors, high glucose suppressed the expression of mature cardiomyocyte markers, TNNT2 and MEF2C. In human, mutation of TnnT2 is tightly associated with hypertrophic cardiomyopathy, dilated cardiomyopathy, and left ventricular noncompaction cardiomyopathy [52-54]. Suppression of TnnT2 may contribute to impaired GR-E14 cardiogenesis under high glucose condition. These findings support the hypothesis that high glucose adversely impacts the entire ES cardiogenesis program. Our recent studies have demonstrated that cellular stress including oxidative stress and endoplasmic reticulum (ER) stress mediates the adverse effect of high glucose in the developing heart $[8,9]$. Future studies will aim to determine whether cellular stress mediates the inhibitory effect of high glucose in ES cell cardiogenesis.

Intracellular $\mathrm{Ca}^{2+}$ is the central regulator of cardiac contractility [55]. It is critically important how $\mathrm{Ca}^{2+}$ is regulated during initiation of contraction of cardiomyocyte under high glucose condition. In the present study, some key regulation proteins in cardiac contractility, including calcium, sodium, potassium channel proteins, 
and calcium in/outflux proteins (RYR2 and SERCA2A), were investigated; however, most of these genes expressed at similar levels under low and high glucose conditions. Two potassium channel proteins, HCN1 and $\mathrm{KCN} 1$, were suppressed by high glucose. In particularly KCN1 was almost completely suppressed by high glucose. The HCN1 protein is highly expressed in the sinoatrial node and is colocalized with $\mathrm{HCN} 4$, the main sinoatrial pacemaker channel isoform [56]. Therefore, high glucose-suppressed HCN1 and KCN1 may contribute to reduced number of contracting cardiomyocytes derived from GR-E14 cells. It is well known that intracellular calcium release from the sarcoplasmic reticulum is required for heart contraction [57]. Since high glucose inhibited ES cell-derived cardiomyocytes contraction, it is important to investigate the relationship between $\mathrm{Ca}^{2+}$ wave profile and contraction frequency. Interestingly, reduced frequency of $\mathrm{Ca}^{2+}$ wave profile under high glucose condition was consistent with slower contraction frequency in differentiated cardiomyocytes compared to that in low glucose condition. These findings suggest that the functionality of cardiomyocytes derived from ES cells is impaired by high glucose.

Our finding indicated that high glucose inhibited GRE14 cell differentiation into cardiomyocytes. However the underlying mechanism needs to be further elucidated. Jang et al. reported that high glucose upregulated ES cell pluripotency through elevated level of O-linked$\mathrm{N}$-acetylglucosamine in proteins of core components of the pluripotency network [58]. Furthermore, ES cells utilize glucose catabolism to maintain a high level of intracellular $\alpha$-ketoglutarate, promoting histone/DNA demethylation and pluripotency [59]. Therefore suppression of ES differentiation by high glucose may be due to high glucose-increased pluripotency, which may ultimately delay ES differentiation. Only one study indicates that high glucose-induced reactive oxygen species (ROS) promotes cardiomyocyte differentiation from ESC cells [40]. Other studies have shown that high glucose enhances the expression of pluripotent markers, OCT4, NANOG, and SOX2, in adipose-derived stem cells through ROS generation [60, 61]. This indirect evidence supports our conclusion that high glucose impairs ES cell differentiation into cardiomyocytes.

\section{Conclusions}

GR-E14 cells adapted to physiological glucose acquire glucose responsiveness. The GR-E14 cell line may be a useful model for investigating the effect of high glucose on early cardiac specification. Our study showed for the first time that high glucose delayed and impaired GR-E14 cardiomyocytes by inhibiting early cardiac specification genes, cardiac transcription factors, and genes essential for cardiomyocyte maturation and contractility. Thus, high glucose inhibits ES cardiogenesis by suppressing gene expression. Our findings guide future ES maintenance and differentiation by showing the adversity of high glucose in ES cardiogenesis and providing the beneficial effects using physiological concentration of glucose at $5 \mathrm{mM}$.

\section{Additional files}

Additional file 1: Table S1. Primer sequences for RT-qPCR. (DOCX $13 \mathrm{~kb}$ ) Additional file 2: Video 1. Cardiomyocyte contraction frequency in low glucose. (AVI 505 kb)

Additional file 3: Video 2. Cardiomyocyte contraction frequency in high glucose. (AVI 829 kb)

\section{Acknowledgements}

Not applicable.

\section{Funding}

This work was supported by the National Institutes of Health (NIH) National Institute of Diabetes and Digestive and Kidney Diseases (NIDDK) grants R01DK083243, R01DK101972, R01DK103024, R01HL131737, and an American Diabetes Association Basic Science Award (1-13-BS-220).

\section{Availability of supporting data}

Original data will be available upon request.

\section{Authors' contributions}

PY contributed to collection and/or assembly of data, and manuscript writing. SK contributed to data analysis and interpretation, and final approval of the manuscript. EAR contributed to data analysis and interpretation, and final approval of the manuscript. XC contributed to collection of data. PY contributed to conception and design, financial support, data analysis and interpretation, and manuscript writing. All authors read and approved the final manuscript.

\section{Authors' information}

All authors are from University of Maryland, Baltimore.

Competing interests

The authors declare that they have no competing interests.

Consent for publication

Not applicable.

Ethical approval and consent to participate Not applicable.

\section{Author details}

1Department of Obstetrics, Gynecology and Reproductive Sciences, University of Maryland School of Medicine, BRB11-039, 655W. Baltimore Street, Baltimore, MD 21201, USA. ²Division of Cardiac Surgery, University of Maryland School of Medicine, Baltimore, MD 21201, USA. ${ }^{3}$ Department of Biochemistry and Molecular Biology, University of Maryland School of Medicine, Baltimore, MD 21201, USA.

Received: 15 September 2016 Revised: 11 November 2016 Accepted: 22 November 2016

Published online: 09 December 2016

References

1. Pauliks LB. The effect of pregestational diabetes on fetal heart function. Expert Rev Cardiovasc Ther. 2015;13(1):67-74.

2. Sukanya S, Bay BH, Tay SS, Dheen ST. Frontiers in research on maternal diabetes-induced neural tube defects: past, present and future. World J Diabetes. 2012;3(12):196-200.

3. Avolio E, Caputo M, Madeddu P. Stem cell therapy and tissue engineering for correction of congenital heart disease. Front Cell Dev Biol. 2015;3:39. 
4. Wang F, Wu Y, Gu H, Reece EA, Fang S, Gabbay-Benziv R, Aberdeen G, Yang P. Ask1 gene deletion blocks maternal diabetes-induced endoplasmic reticulum stress in the developing embryo by disrupting the unfolded protein response signalosome. Diabetes. 2015;64(3):973-88.

5. Wang F, Reece EA, Yang P. Oxidative stress is responsible for maternal diabetes-impaired transforming growth factor beta signaling in the developing mouse heart. Am J Obstet Gynecol. 2015;212(5):650. e1-11.

6. Wang F, Reece EA, Yang P. Advances in revealing the molecular targets downstream of oxidative stress-induced proapoptotic kinase signaling in diabetic embryopathy. Am J Obstet Gynecol. 2015;213(2):125-34.

7. Gabbay-Benziv R, Reece EA, Wang F, Yang P. Birth defects in pregestational diabetes: Defect range, glycemic threshold and pathogenesis. World J Diabetes. 2015;6(3):481-8.

8. Gu H, Yu J, Dong D, Zhou Q, Wang JY, Fang S, Yang P. High glucose-repressed CITED2 expression through miR-200b triggers the unfolded protein response and endoplasmic reticulum stress. Diabetes. 2016;65(1):149-63.

9. Wang F, Weng H, Quon MJ, Yu J, Wang JY, Hueber AO, Yang P. Dominant negative FADD dissipates the proapoptotic signalosome of the unfolded protein response in diabetic embryopathy. Am J Physiol Endocrinol Metab. 2015;309(10):E861-73.

10. Wu Y, Wang F, Reece EA, Yang P. Curcumin ameliorates high glucoseinduced neural tube defects by suppressing cellular stress and apoptosis. Am J Obstet Gynecol. 2015;212(6):802. e1-8.

11. Yang P, Reece EA, Wang F, Gabbay-Benziv R. Decoding the oxidative stress hypothesis in diabetic embryopathy through proapoptotic kinase signaling. Am J Obstet Gynecol. 2015;212(5):569-79.

12. Wu Y, Wang F, Fu M, Wang C, Quon MJ, Yang P. Cellular stress, excessive apoptosis, and the effect of metformin in a mouse model of type 2 diabetic embryopathy. Diabetes. 2015;64(7):2526-36.

13. Kumar SD, Dheen ST, Tay SS. Maternal diabetes induces congenital heart defects in mice by altering the expression of genes involved in cardiovascular development. Cardiovasc Diabetol. 2007:6:34

14. Boheler KR, Czyz J, Tweedie D, Yang HT, Anisimov SV, Wobus AM. Differentiation of pluripotent embryonic stem cells into cardiomyocytes. Circ Res. 2002;91(3):189-201.

15. Thomson JA, Itskovitz-Eldor J, Shapiro SS, Waknitz MA, Swiergiel JJ, Marshall VS, Jones JM. Embryonic stem cell lines derived from human blastocysts. Science. 1998;282(5391):1145-7.

16. Martin GR. Isolation of a pluripotent cell line from early mouse embryos cultured in medium conditioned by teratocarcinoma stem cells. Proc Natl Acad Sci U S A. 1981;78(12):7634-8

17. Mohamad O, Yu SP, Chen D, Ogle M, Song M, Wei L. Efficient neuronal differentiation of mouse ES and iPS cells using a rotary cell culture protocol. Differentiation. 2013;86(4-5):149-58.

18. Wataya T, Ando S, Muguruma K, Ikeda H, Watanabe K, Eiraku M, Kawada M, Takahashi J, Hashimoto N, Sasai Y. Minimization of exogenous signals in ES cell culture induces rostral hypothalamic differentiation. Proc Natl Acad Sci U S A. 2008;105(33):11796-801.

19. Boheler KR. ES cell differentiation to the cardiac lineage. Methods Enzymol. 2003;365:228-41

20. Era T, Takagi T, Takahashi T, Bories JC, Nakano T. Characterization of hematopoietic lineage-specific gene expression by ES cell in vitro differentiation induction system. Blood. 2000;95(3):870-8.

21. Drab M, Haller H, Bychkov R, Erdmann B, Lindschau C, Haase H, Morano I, Luft FC, Wobus AM. From totipotent embryonic stem cells to spontaneously contracting smooth muscle cells: a retinoic acid and db-cAMP in vitro differentiation model. FASEB J. 1997;11(11):905-15.

22. Ao A, Hao J, Hopkins CR, Hong CC. DMH1, a novel BMP small molecule inhibitor, increases cardiomyocyte progenitors and promotes cardiac differentiation in mouse embryonic stem cells. PLoS One. 2012;7(7):e41627.

23. Sun $M$, Yan X, Bian Y, Caggiano AO, Morgan JP. Improving murine embryonic stem cell differentiation into cardiomyocytes with neuregulin-1: differential expression of microRNA. Am J Physiol Cell Physiol. 2011;301(1):C21-30

24. Law SK, Leung CS, Yau KL, Tse CL, Wong CK, Leung FP, Mascheck L, Huang $Y$, Sauer H, Tsang SY. Regulation of multiple transcription factors by reactive oxygen species and effects of pro-inflammatory cytokines released during myocardial infarction on cardiac differentiation of embryonic stem cells. Int J Cardiol. 2013;168(4):3458-72.

25. Burridge PW, Matsa E, Shukla P, Lin ZC, Churko JM, Ebert AD, Lan F, Diecke S, Huber B, Mordwinkin NM, et al. Chemically defined generation of human cardiomyocytes. Nat Methods. 2014;11(8):855-60.
26. Kleman AM, Yuan JY, Aja S, Ronnett GV, Landree LE. Physiological glucose is critical for optimized neuronal viability and AMPK responsiveness in vitro. J Neurosci Methods. 2008;167(2):292-301.

27. Kuehn MR, Bradley A, Robertson EJ, Evans MJ. A potential animal model for Lesch-Nyhan syndrome through introduction of HPRT mutations into mice. Nature. 1987;326(6110):295-8.

28. Ali NN, Xu X, Brito-Martins M, Poole-Wilson PA, Harding SE, Fuller SJ. Betaadrenoceptor subtype dependence of chronotropy in mouse embryonic stem cell-derived cardiomyocytes. Basic Res Cardiol. 2004;99(6):382-91.

29. Zhao G, Li T, Brochet DX, Rosenberg PB, Lederer WJ. STIM1 enhances SR $\mathrm{Ca} 2+$ content through binding phospholamban in rat ventricular myocytes. Proc Natl Acad Sci U S A. 2015;112(34):E4792-801.

30. Jung JH, Wang XD, Loeken MR. Mouse embryonic stem cells established in physiological-glucose media express the high KM Glut2 glucose transporter expressed by normal eEmbryos. Stem Cells Transl Med. 2013;2(12):929-34.

31. Vijaya M, Manikandan J, Parakalan R, Dheen ST, Kumar SD, Tay SS. Differential gene expression profiles during embryonic heart development in diabetic mice pregnancy. Gene. 2013;516(2):218-27.

32. Lisowski LA, Verheijen PM, Copel JA, Kleinman CS, Wassink S, Visser GH, Meijboom EJ. Congenital heart disease in pregnancies complicated by maternal diabetes mellitus. An international clinical collaboration, literature review, and meta-analysis. Herz. 2010;35(1):19-26.

33. Glass C, Singla R, Arora A, Singla DK. Mouse embryonic stem cell-derived cardiac myocytes in a cell culture dish. Methods Mol Biol. 2015;1299:145-52.

34. Fuegemann CJ, Samraj AK, Walsh S, Fleischmann BK, Jovinge S, Breitbach M. Differentiation of mouse embryonic stem cells into cardiomyocytes via the hanging-drop and mass culture methods. Curr Protoc Stem Cell Biol. 2010; 15:F:1F.11:1F.11.1-1F.11.13. http://onlinelibrary.wiley.com/doi/10.1002/ 9780470151808.sc01f11s15/abstract.

35. Edwards JN, Blatter LA. Cardiac alternans and intracellular calcium cycling. Clin Exp Pharmacol Physiol. 2014:41(7):524-32

36. Maier LS, Bers DM. Role of Ca2+/calmodulin-dependent protein kinase (CaMK) in excitation-contraction coupling in the heart. Cardiovasc Res. 2007; 73(4):631-40.

37. Qu Y, Whitaker GM, Hove-Madsen L, Tibbits GF, Accili EA. Hyperpolarizationactivated cyclic nucleotide-modulated 'HCN' channels confer regular and faster rhythmicity to beating mouse embryonic stem cells. J Physiol. 2008; 586(3):701-16.

38. Sarre A, Pedretti S, Gardier S, Raddatz E. Specific inhibition of HCN channels slows rhythm differently in atria, ventricle and outflow tract and stabilizes conduction in the anoxic-reoxygenated embryonic heart model. Pharmacol Res. 2010;61(1):85-91.

39. Wamstad JA, Alexander JM, Truty RM, Shrikumar A, Li F, Eilertson KE, Ding H, Wylie JN, Pico AR, Capra JA, et al. Dynamic and coordinated epigenetic regulation of developmental transitions in the cardiac lineage. Cell. 2012; 151(1):206-20.

40. Crespo FL, Sobrado VR, Gomez L, Cervera AM, McCreath KJ. Mitochondrial reactive oxygen species mediate cardiomyocyte formation from embryonic stem cells in high glucose. Stem Cells. 2010;28(7):1132-42.

41. Arshi A, Nakashima Y, Nakano H, Eaimkhong S, Evseenko D, Reed J, Stieg AZ, Gimzewski JK, Nakano A. Rigid microenvironments promote cardiac differentiation of mouse and human embryonic stem cells. Sci Technol Adv Mater. 2013;14(2):025003. https://www.ncbi.nlm.nih.gov/pmc/articles/ PMC3845966/.

42. Chen M, Lin YQ, Xie SL, Wu HF, Wang JF. Enrichment of cardiac differentiation of mouse embryonic stem cells by optimizing the hanging drop method. Biotechnol Lett. 2011;33(4):853-8.

43. Holemans K, Gerber RT, Meurrens K, De Clerck F, Poston L, Van Assche FA. Streptozotocin diabetes in the pregnant rat induces cardiovascular dysfunction in adult offspring. Diabetologia. 1999:42(1):81-9.

44. Mummery CL, Zhang J, Ng ES, Elliott DA, Elefanty AG, Kamp TJ. Differentiation of human embryonic stem cells and induced pluripotent stem cells to cardiomyocytes: a methods overview. Circ Res. 2012; 111(3):344-58.

45. Bondue A, Blanpain C. Mesp1: a key regulator of cardiovascular lineage commitment. Circ Res. 2010;107(12):1414-27.

46. Bondue A, Tannler S, Chiapparo G, Chabab S, Ramialison M, Paulissen C, Beck B, Harvey R, Blanpain C. Defining the earliest step of cardiovascular progenitor specification during embryonic stem cell differentiation. J Cell Biol. 2011;192(5):751-65. 
47. Korzh V, Grunwald D. Nadine Dobrovolskaia-Zavadskaia and the dawn of developmental genetics. Bioessays. 2001;23(4):365-71.

48. Ng ES, Azzola L, Sourris K, Robb L, Stanley EG, Elefanty AG. The primitive streak gene Mixl1 is required for efficient haematopoiesis and BMP4induced ventral mesoderm patterning in differentiating ES cells. Development. 2005;132(5):873-84.

49. Hart AH, Hartley L, Sourris K, Stadler ES, Li R, Stanley EG, Tam PP, Elefanty AG, Robb L. Mixl1 is required for axial mesendoderm morphogenesis and patterning in the murine embryo. Development. 2002;129(15):3597-608.

50. Lien CL, Wu C, Mercer B, Webb R, Richardson JA, Olson EN. Control of early cardiac-specific transcription of Nkx2-5 by a GATA-dependent enhancer. Development. 1999;126(1):75-84.

51. Balci MM, Akdemir R. NKX2.5 mutations and congenital heart disease: is it a marker of cardiac anomalies? Int J Cardiol. 2011;147(3):e44-5.

52. Luedde M, Ehlermann P, Weichenhan D, Will R, Zeller R, Rupp S, Muller A, Steen $\mathrm{H}$, Ivandic BT, Ulmer HE, et al. Severe familial left ventricular noncompaction cardiomyopathy due to a novel troponin T (TNNT2) mutation. Cardiovasc Res. 2010;86(3):452-60.

53. Komamura K, Iwai N, Kokame K, Yasumura Y, Kim J, Yamagishi M, Morisaki T, Kimura A, Tomoike H, Kitakaze M, et al. The role of a common TNNT2 polymorphism in cardiac hypertrophy. J Hum Genet. 2004;49(3):129-33.

54. Van Acker H, De Sutter J, Vandekerckhove K, de Ravel TJ, Verhaaren H, De Backer J. Dilated cardiomyopathy caused by a novel TNNT2 mutation-added value of genetic testing in the correct identification of affected subjects. Int J Cardiol. 2010;144(2):307-9.

55. Bers DM. Calcium fluxes involved in control of cardiac myocyte contraction. Circ Res. 2000;87(4):275-81.

56. Fenske S, Krause SC, Hassan SI, Becirovic E, Auer F, Bernard R, Kupatt C, Lange $P$, Ziegler T, Wotjak $C$, et al. Sick sinus syndrome in HCN1-deficient mice. Circulation. 2013;128(24):2585-94.

57. Marks AR. Calcium and the heart: a question of life and death. J Clin Invest. 2003;111(5):597-600.

58. Jang H, Kim TW, Yoon S, Choi SY, Kang TW, Kim SY, Kwon YW, Cho EJ, Youn HD. O-GICNAC regulates pluripotency and reprogramming by directly acting on core components of the pluripotency network. Cell Stem Cell. 2012; 11(1):62-74

59. Carey BW, Finley LW, Cross JR, Allis CD, Thompson CB. Intracellular alphaketoglutarate maintains the pluripotency of embryonic stem cells. Nature. 2015;518(7539):413-6.

60. Dentelli P, Barale C, Togliatto G, Trombetta A, Olgasi C, Gili M, Riganti C, Toppino M, Brizzi MF. A diabetic milieu promotes OCT4 and NANOG production in human visceral-derived adipose stem cells. Diabetologia. 2013;56(1):173-84.

61. Cheng NC, Hsieh TY, Lai HS, Young TH. High glucose-induced reactive oxygen species generation promotes stemness in human adipose-derived stem cells. Cytotherapy. 2016;18(3):371-83.

\section{Submit your next manuscript to BioMed Central and we will help you at every step:}

- We accept pre-submission inquiries

- Our selector tool helps you to find the most relevant journal

- We provide round the clock customer support

- Convenient online submission

- Thorough peer review

- Inclusion in PubMed and all major indexing services

- Maximum visibility for your research

Submit your manuscript at www.biomedcentral.com/submit

\section{() Biomed Central}

